\title{
Study on the Influence of Environmental Protection Investment on GDP in China
}

\author{
Chenggang Li, Lingyun Luo, Yandan Xue, Xiaoliang Liu, Mingguo Zhang and \\ Wulin Zhang \\ Faculty of Finance, Guizhou University of Finance and Economics, Guiyang, China
}

Keywords: Green economy; Environmental protection investment; GDP; Multivariate regression model

\begin{abstract}
In recent years, due to the serious environmental problems, building friendly environment and sustainable society has gained people's attention. Studying on the influence of environmental protection investment on economic growth is benefit for the development of green economy in China. Using the data from 2004 to 2014, this paper constructs the multivariate regression model to empirically analyze the influence of environmental protection investment on GDP growth. The empirical results show that the investment of environmental pollution control, the investment of industrial pollution control project and energy saving and environmental protection have a positive effect on GDP growth.
\end{abstract}

\section{Introduction}

In recent years, with the rapid development of China' economy, people's living standards have been improved significantly. But the development of economy brings many problems, such as pollution and environmental problems which have gained great attention by the government. The 16th National Congress of the Communist Party of China has put forward the target of the development of low carbon economy, circular economy and resources saving and environment friendly society. The seventh session and fifth plenary session will write the green development into "the Twelfth Five Year Plan". In addition, the 18th National Congress emphasized on the build of ecological civilization construction.

The environmental protection investment (EPI) has huge economic benefits. Regardless of near or long-term period, actively increases investment in the environmental industrial and develop environment industry are the wise decision for the sustainable development. Currently, the EPI level in our country is low; the utility ratio of the investment is relatively low, and the investment structure still need to be improved. To make the environmental protection industry as the new economic point of China' economic growth, the government needs to increase investment in environmental protection, improve the efficiency of input and output, and finally achieve continuous rapid and healthy development of national economy and social improvement.

\section{Literature Review}

The increase of environmental protection investment (EPI) in China may have positive effect on economic growth. As can be known from the neoclassical economics growth theory, economic growth is determined by capital growth rate, labor growth rate and the marginal productivity; therefore, we can draw the conclusion that, environmental protection investment, as a source of capital formation, can directly influence the growth of economy. Capital formation refers to the raise of capital stock in an economy, including the increase of new plant, machinery and equipment purchase and infrastructure, etc., thus leading to the increase of the total social investment, and finally contributes to the growth of economy. EPI is a kind of relatively independent and special investment in national economy and social development. Li and Zhang (1995) ${ }^{[1]}$ declares that the EPI would bring impact on the economy. Because the EPI has two main sources: one is the newly added investors, another is an adjustment of the existing resources stock. Introduce of large number of EPI may lead to the reconfiguration of resource inevitably, and therefore influence on the 
economy. However, there is no exact conclusion of this conclusion. Pearce and Warford (1997) ${ }^{[2]}$ study on the influence of environmental protection expenditure on GNP in the OECD countries. They find out that the effect of environmental protection expenditure on GNP of these countries has not been clearly defined. In the first year, all the environmental protection plans are beneficial to the growth of GNP, but the influence of them is complex in the final year, where both positive and negative effects on the growth of GNP are found in different countries. Overall, the negative impact of EPI on GNP is less than $1 \%$ of the total amount of GNP. Studies also show that, EPI has a positive influence on inflation and leading to the increase of inflation rate by $0.3 \% \sim 0.5 \%$. Jiang et al. (2005) ${ }^{[3]}$ believe that investment and EPI have big differences in the aspect of investment returns. Wang and Yang $(2008)^{[4]}$ use co-integration test, error correction model and Granger causality test to study the relationship of EPI and GDP, and their results show that the EPI could boost GDP growth in China. Wang et al. (2009) ${ }^{[5]}$ analyze the relationship between EPI and economic growth, and they find that there is no significant correlation between the growth rate of EPI and economic, and in terms of long period, there is a long-term equilibrium relationship between the growth rate of fiscal revenue and EPI. Lei et al. (2010) ${ }^{[6]}$ use econometric OLS (least squares) for the regression testing of the relationship between EPI and economic growth of China; and the results reveal that the EPI has positive effects on economic growth. He et al. (2013) ${ }^{[7]}$ use the panel data model to analyze the relationship between the environmental protection industry and EPI, and the results show that EPI can regulate the degree of environmental protection industry. Wang et al. (2014) ${ }^{[8]}$ study on the total amount of EPI, the constitution of EPI and the regional investment of EPI during 2005-2011. The studies show that there is an increase trend in the overall EPI of China. However, there is a lack of effective investment scale in the pollution control. What's more, the EPI is quite different among different districts. Zhu et al. (2014) ${ }^{[9]}$ use cointegration, error correction model and Granger causality test method in their study, and they find that there is a long-term equilibrium relationship between GDP and EPI. Through the expansion of the Gini index, Lu et al. (2015) ${ }^{[10]}$ put forward to take contribution coefficient of industry as the judgment factor, and the results reveal that the Geni coefficient of China's environmental protection industry shows ascendant trend in recent years.

All the literature mentioned above provided helpful discussion on the positive effects of EPI on the promotion of GDP. However, some of the literature were only about qualitative analysis, not quantitative analysis. Some of the literature made use of the data, which are too old or too less. Some of the literature used too less of variables. In this paper, we use multiple regression models to construct a multiple regression model, and empirically analyze the impact of EPI on the GDP growth.

\section{Empirical Analysis}

Empirical Model Building. In this paper, a multiple regression model was constructed, and Eviews software was used to estimate the model. Using the least square method for the regression analysis of energy-conserving and environment-protective cost, total investment of environmental pollution, industrial pollution control projects to GDP, this paper empirically analyzes the impact of EPI on GDP growth. The multiple regression model built in this paper is shown as follows:

$$
G D P=\alpha+\beta_{1} E I+\beta_{2} I I+\beta_{3} F P E+\varepsilon
$$

Where, GDP is gross domestic product in China, EI represents the total amount of investment in pollution control, II is the completed investment of industrial pollution control project, and FPE is the central government budget public expenditure balance sheet used in energy conservation and environmental protection.

List of Data Sources. The data sources of the energy-conserving and environment-protective cost in China's central government public expenditure during 2006 to 2014 were found from the website of "the schedule of the central public finance expenditure in Ministry of Finance". The data sources of year 2004 and 2005 were found from the "China finance Yearbook 2004"and" China 
Financial Yearbook 2005" respectively. The total investment amount of pollution control and the completed investment of industrial pollution control projects were found from the "national environment statistical bulletin" of environment ministry, and GDP data were from the bureau of statistics website. The data used in this paper are listed in Table 1.

Table 1 Data

\begin{tabular}{|l|l|l|l|l|}
\hline year & EI & II & FPE & GDP \\
\hline 2004 & 1908.6 & 308.1 & 93.69 & 160714.4 \\
\hline 2005 & 2388 & 458.2 & 132.97 & 185895.8 \\
\hline 2006 & 2567.8 & 483.9 & 161.24 & 217656.6 \\
\hline 2007 & 3387.6 & 552.4 & 995.82 & 268019.4 \\
\hline 2008 & 4490.3 & 542.6 & 1451.36 & 316751.7 \\
\hline 2009 & 4525.2 & 442.5 & 1934.04 & 345629.2 \\
\hline 2010 & 6654.2 & 397 & 2441.98 & 408903 \\
\hline 2011 & 6026.2 & 444.4 & 2640.98 & 484123.5 \\
\hline 2012 & 8253.6 & 500.5 & 2963.46 & 534123 \\
\hline 2013 & 9037.2 & 849.66 & 3935.15 & 588018.8 \\
\hline 2014 & 9575.5 & 997.7 & 3752.2 & 636138.7 \\
\hline
\end{tabular}

\section{Empirical Regression Results}

Using Eviews software to do the least squares regression, the regression results are collected in Table 2.

Table 2 Regression results

\begin{tabular}{|l|l|l|l|l|}
\hline Variable & Coefficient & Std. Error & t-Statistic & Prob. \\
\hline C & 97813.51 & 32513.49 & 3.008397 & 0.0197 \\
\hline EI & 28.08184 & 15.81075 & 1.776123 & 0.1190 \\
\hline II & 37.62604 & 59.55219 & 0.631816 & 0.5476 \\
\hline FPE & 58.21253 & 29.37693 & 1.981573 & 0.0880 \\
\hline R-squared & 0.982019 & Mean dependent var & 376906.7 \\
\hline Adjusted R-squared & 0.974312 & S.D. dependent var & 165542.7 \\
\hline S.E. of regression & 26532.19 & Akaike info criterion & 23.48539 \\
\hline Sum squared resid & $4.93 E+09$ & Schwarz criterion & 23.63008 \\
\hline Log likelihood & -125.1697 & Hannan-Quinn criter. & 23.39419 \\
\hline F-statistic & 127.4303 & Durbin-Watson stat & 2.466756 \\
\hline Prob(F-statistic) & 0.000002 & \multicolumn{2}{|}{} & \\
\hline
\end{tabular}

From Table 2 we can find out that the adjusted R2 is 0.974312 , statistic value $\mathrm{F}$ is 127.4303 , and the adjoin probability is 0.000002 , which means, the model shows good estimation results.

According to the estimation results of Table 2, we can get the influence model of the EPI to GDP growth as follows:

$$
G D P=97813.51+28.08184 E I+37.62604 I I+58.21253 F P E
$$

The estimation results of Table 2 show that: (1) when II and FPE are invariable, every increase of 100 million (RMB) EI, can get 2.808 billion GDP growth; (2) when EI and FPE are invariable, every increase of 100 million II, can get 3.763 billion GDP growth; (3) when EI and II are invariable, every increase of 100 million FPE, can get 5.821 billion GDP growth. 


\section{Conclusions and Policy Suggestions}

This paper uses data from 2004 to 2014 of China and multivariate regression model for the empirical analysis of the influence of the environmental protection investment to GDP growth. The empirical results showed that: (1) when II and FPE are invariable, every increase of 100 million (RMB) EI can get 2.808 billion GDP growth; (2) when EI and FPE are invariable, every increase of 100 million II, can get 3.763 billion GDP growth; (3) when EI and II are invariable, every increase of 100 million FPE, can get 5.821 billion GDP growth. Therefore, the investment of environmental pollution control, industrial pollution control project and energy saving and environmental protection have a positive effect on GDP.

According to the research results, we put forward the following suggestions:

Firstly, the government should strengthen the investment in environmental protection. The government should increase the policy support for environmental protection industry, further maintain continuously investment in the environmental protection industry, and increase the central fiscal expenditure and improve the living environment of residents.

Secondly, the government should broaden the source of environmental protection investment funds. In terms of the capital source in environmental protection, we should use a variety of financial instruments to increase the investment in the environmental protection industry. Government and private capital cooperation model (PPP model) and green credit policy can be used for the financing of environmental protection.

\section{References}

[1] Y. Li, Z. Zhang. Environmental economics [M]. China planning press, 1995: 152-160.

[2] D. Pearce, J. Warford. World Without End: Economics, Environment and Sustainable Development.China Financial and Economic Publishing House, 1996

[3] H. Jiang, D. Cao, J. Wang. The Study on Action Principle of Environmental Protection Investment on Nation Economy and the Contribution Models [J]. Research of Environmental Science, 2005, (1): 71 - 74

[4] J. Wang, W. Yang. A Study on Interaction between China's EPI and Growth of Economy [J]. Economic Management, 2008, (21-22): 157-162

[5] J. Wang, Y. Lu, S. Wu. Correlation Analysis between Environmental Protection Investment and Macro-economic Growth [J]. China Population, Resources and Environment, 2009, (4): 1-6.

[6] S. Lei, Y. He. Regression analysis of Investment in Environmental Protection and Economic Growth in China [J]. Journal of Northwestern Polytechnical University (Social Science Edition), 2010, (2): 20-22.

[7] L. He, J. Zhu, D. Bian. Research on the Effect of China's Environmental Protection Investment to the Environmental Protectionon Industry Development -An Empirical Analysis Based on the National and Regional data [J]. Soft Science, 2013, 27 (1): 37-41

[8] X. Wang, X. Feng, G. Tang. Study on the Trends and Problems of China Environmental Investment [J]. Environmental Monitoring in China, 2014, (1): 181-186.

[9] J. Zhu, S. Xu, Y. Lu. Empirical Research on China Environmental Protection Investment and Economic Growth Based on Error Correction Model and Grainger Causality [J]. China Population, Resources and Environment, 2014, (11): 100-103.

[10] Y. Lu, S. Wu, Y. Zhao. Analysis of Spatial Equilibrium of Environmental Industry Development Based on the Environmental Protection Input: A Case Study of the Period between 2004 and 2011. [J]. China Environmental Science, 35 (5): 1586-1591. 